\title{
Epistemologia, Complexidade e Multiculturalismo: Uma Reflexão Necessária Para uma Pesquisa Científica do Direito
}

\section{Patrícia Inês Jablonski}

Advogada. Foi professora-visitante na Faculdade de Educação e Tecnologia da Região Missioneira - Fetremis/RS -, atuando na disciplina de Educação, Diversidade e Desigualdade (2016) e professora-pesquisadora no Instituto Federal Farroupilha - IFFar -, Campus Santa Rosa (2016). Graduada em Direito pela Universidade Regional Integrada do Alto Uruguai e das Missões/RS (2013). Especialista em Direito Processual Civil pelo Centro Universitário Internacional - Uninter - (2015) e mestre em Direito pelo Programa de Pós-Graduação Stricto Sensu - Mestrado em Direito - da Universidade Regional Integrada do Alto Uruguai e das Missões/RS (2016). patriciajablonskiadv@hotmail.com

\section{Resumo}

0 presente artigo tem como escopo abordar a compreensão da complexidade por meio de uma reflexão orientada pela multiplicidade, objetivando investigar a possibilidade da utilização deste pensamento para se fazer pesquisa científica na área do Direito, ao adotar como ponto de partida uma leitura epistemológica complexo-sistêmica. As principais questões a serem enfrentadas são: a demonstração de uma epistemologia intricada na compreensão dessa ordem heterogênea pelo Direito; a compreensão do multiculturalismo e da necessidade sistêmica pelas sociedades multiculturais, bem como 0 imperativo de respostas adequadas em Direito às exigências da sociedade contemporânea. A metodologia de abordagem qualitativa, de método dialógico, em pesquisa teórica, traz coleta de dados bibliográficos e análise de dados de conteúdo. 0 artigo procura demonstrar, em um contexto contemporâneo de contingência, intersubjetivismo, de autorreprodução e de conexão em rede, algumas características que dão forma à sociedade contemporânea e que desvelam, por sua vez, novos desafios à pesquisa científica, nos impondo a necessidade de uma nova leitura ou até mesmo de criação de pressupostos de interpretação e compreensão da sociedade contemporânea.

Palavras-chave: Epistemologia. Complexidade. Multiculturalismo. Pesquisa científica. 


\title{
Epistemology, Complexity and Multiculturalism: A Reflection Needed for Scientific Research Law
}

\begin{abstract}
The present article has as scope to approach the understanding of complexity through a multiplicity oriented reflection, aiming to investigate the possibility of using this thought to do scientific research in the area of Law, adopting as a starting point a complex-systemic epistemological reading . The main issues to be addressed are: the demonstration of an intricate epistemology in the understanding of this heterogeneous order by law; the understanding of multiculturalism and the systemic need for multicultural societies, as well as the imperative of adequate responses in Law to the demands of contemporary society. The methodology of qualitative approach, of dialogical method, in theoretical research, brings collection of bibliographic data and analysis of content data. The article seeks to demonstrate, in a contemporary context of contingency, intersubjectivism, self - reproduction and networking, some characteristics that give shape to contemporary society and which reveal, in turn, new challenges to scientific research, imposing on us the need for a new reading or even the creation of presuppositions of interpretation and understanding of contemporary society.
\end{abstract}

Keywords: Epistemology. Complexity. Multiculturalism. Scientific research.

Recebido em: 19/5/2016

Revisões requeridas em: 7/6/2016

Aceito em: 13/6/2016

\section{Sumário}

1 Introdução. 2 Epistemologia jurídica e complexidade - uma breve sistematização dos principais paradigmas. 2.1 Hans Kelsen e a ilibada ciência do Direito. 2.2 Hart e Dworkin - o Direito como modelo sociocomportamental (de integridade). 2.3 Niklas Luhmann - o Direito no contexto dos sistemas sociais autopoiéticos. 3 Lógica autopoiética. 4 Complexidade e multiculturalismo: uma reflexão necessária para o direito. 5 Como fazer ciência do direito na complexidade? 6 Considerações finais. 7 Referências. 


\section{INTRODUÇÃO}

A epistemologia jurídica é a teoria do Direito (em oposição a teorias de Direito); é o ramo do conhecimento jurídico-filosófico que se preocupa, de certa forma, consigo mesmo. Atenta-se com o seu objeto, com o seu método, com os seus pressupostos, com a sua natureza e com a sua própria validade. Além disso, preocupa-se com a relação deste conhecimento jurídico com os demais ramos do conhecimento, com a situação do Direito neste quadro de complexidade vivenciado atualmente. Opta-se, neste trabalho, pela divisão da epistemologia jurídica em paradigmas, ressaltando-se apenas os aspectos mais relevantes de cada paradigma no desenvolvimento da parte histórica. Não é e não pretende (nem poderia) ser uma análise ou sistematização completa dos paradigmas jurídicos abordados. Aporta-se, também, a demonstração da possibilidade de desenvolvimento de uma nova epistemologia de compreensão, da necessidade de adequada compreensão da complexidade e do multiculturalismo, para que possamos desenvolver uma nova interpretação e compreensão da sociedade e da ciência do Direito.

Nessa seara, o objetivo principal desta investigação reside na possibilidade da utilização do pensamento complexo para se fazer pesquisa científica do Direito. Partindo da problematização da possibilidade de se fazer uma pesquisa científica complexa do Direito, nossa hipótese habita na seguinte consideração: sendo o Direito um saber humano que não se restringe ao seu componente formal, mas que encontra fundamento na própria sociedade, ele é um ente complexo. Por conseguinte, a pesquisa científica do Direito deve ser igualmente complexa, sob pena de reduzirmos o Direito ao direito positivo e de transformarmos a pesquisa científica numa pesquisa comprobatória? 


\section{EPISTEMOLOGIA JURÍDICA E COMPLEXIDADE - Uma Breve Sistematização dos Principais Paradigmas}

\subsection{Hans Kelsen e a ilibada ciência do Direito}

O jurista e filósofo austríaco Hans Kelsen historiou a sua Teoria Pura do Direito em 1934. Com efeito, o referido trabalho - geralmente apontado como um dos expoentes do juspositivismo - não deve, nem pode, ser reduzido a este rótulo. Nele, Kelsen discorre sobre a própria natureza do Direito, suas relações com a moral e com os demais saberes, normoestática e normodinâmica, a relação do Direito com o Estado, o Direito internacional e a hermenêutica jurídica. O propósito declarado da Teoria Pura era "responder a esta questão: O que é e como é o Direito?" (KELSEN, 1998, p. 1).

A resposta proposta por Kelsen iniciava-se pela definição do Direito como uma ordem normativa (que regula a conduta humana), coativa (imponível por sanção) e única (que exclui do seu âmbito de aplicação outras ordens concorrentes) (KELSEN, 1998, p. 33-55). ${ }^{1}$

Nesse sentir, afirma que o fundamento de validade de tal ordem seria uma norma fundamental hipotética, ${ }^{2}$ da qual se retira a validade de todas as demais normas, sujeitas a uma hierarquia normativa superior.

Nas palavras do autor:

\footnotetext{
1 "Ordem" sendo entendida, no contexto da Teoria Pura do Direito, como um sistema de normas cuja unidade decorre do fato de todas terem o mesmo fundamento de validade.

${ }^{2} \mathrm{O}$ epistemologista alemão Hans Albert, ao formular o Trilema de Münchhausen, defendeu que, no fundamento filosófico de toda a teoria há, em algum ponto, um de três procedimentos inválidos: uma petição de princípio/argumento de autoridade, uma regressão infinita ou uma escolha arbitrária. Vê-se que Kelsen optou, muito explicitamente, por uma escolha arbitrária.
} 
A resposta epistemológica (teorético-gnoseológica) da Teoria Pura do Direito [para a questão sobre a existência de normas jurídicas objetivamente válidas descritíveis em proposições jurídicas] é: sob a condução de pressupormos a norma fundamental: devemos conduzir-nos como a Constituição prescreve, quer dizer, de harmonia com o sentido subjetivo do ato de vontade constituinte, de harmonia com as prescrições do autor da Constituição. A função dessa norma fundamental é: fundamentar a validade objetiva de uma ordem jurídica positiva, isto é, das normas, postas através de atos de vontade humanos, de uma ordem coerciva globalmente eficaz, quer dizer: interpretar o sentido subjetivo destes atos como seu sentido objetivo (KELSEN, 1998, p. 225-226).

Ademais, a ideia de uma Teoria Pura implicava necessária separação do Direito e da moral. Logo, para sustentá-la, Kelsen defende que a inexistência de uma moral absoluta (ou de uma justiça absoluta) desautorizava a adoção dela como "medida ou padrão absoluto para a valoração de uma ordem jurídica positiva” (1998, p. 76), de forma que "uma norma jurídica pode ser considerada como válida ainda que contrarie a ordem moral”, devendo ser considerada apenas em relação ao restante da ordem jurídica $(1998$, p. 77,131$)$.

Sob tal enfoque, não seria função da ciência do Direito justificar uma ordem normativa, legitimá-la ou avaliar a sua adequação moral ou a sua justiça, ${ }^{3}$ pois apenas ser-lhe-ia dado conhecê-la e descrevê-la. A abordagem de Kelsen da relação entre o Direito e os demais saberes portanto, previsivelmente não destoa da concepção da relação entre Direito e moral (1998, p. 113-119).

Como pode ser notado, Kelsen recrimina a noção de que possa haver uma sociologia jurídica, por exemplo, pois das considerações sociológicas não se deve ocupar a ciência jurídica, na medida em que a socio-

${ }^{3}$ Merece destaque o fenômeno de tal ideia: de que o Direito (entendido como sistema, e não como normas específicas) não se justifica nem se legitima dentro de si mesmo; valida-se, apenas. 
logia relaciona “os fatos da ordem do ser" com outros fatos da ordem do ser - paralelos ao Direito, sem coincidir com ele - e não com normas válidas (1998, p. 113).

Por fim, é relevante notar que o autor reputa equívoca o uso da expressão “fontes do Direito” no contexto da Teoria Pura. Entende que ela pode designar duas ideias diferentes: tanto os métodos de criação jurídica em geral quanto todos os fatos não jurídicos que influenciam essa atividade de criação - e, para Kelsen, a ciência do Direito não deve se ocupar deste segundo tipo (1998, p. 258-259).

\subsection{Hart e Dworkin - o Direito como modelo sociocomportamental (de integridade)}

A edificação da epistemologia de Hart tomou por base três questões recorrentes na teoria do Direito ainda não respondidas satisfatoriamente: "Como difere o Direito de ordens baseadas em ameaças e como se relaciona com estas? Como difere a obrigação jurídica da obrigação moral e como está relacionada com esta? O que são regras e em que medida é o direito uma questão de regras?” (HART, 1996, p. 18).

Hart era crítico da noção de que o Direito corresponde a uma ordem coativa (positivismo), pois esta, era apenas capaz de descrever adequadamente o direito criminal (HART, 1996, p. 26-35).

À vista disso, Hart prefere dividir um sistema normativo entre regras primárias e secundárias, em que aquelas visam a determinar comportamentos que, aceitos majoritariamente, permitam a convivência social (obrigações ou deveres); contudo, sendo essencialmente pré-jurídicas, apresentam-se ocasionalmente incertas, estáticas e ineficazes. Por outro lado, as regras secundárias, detendo caráter propriamente jurídico, contém regras de reconhecimento, de alteração e de julgamento e, portanto, provêm de poderes públicos ou privados (HART, 1996, p. 101-109). 
É importante notar que, para Hart, a validade de uma regra é aferida pela sua avaliação diante de uma regra de reconhecimento. Por conseguinte, a validade das próprias regras de reconhecimento seria aferida pela avaliação ante a regras superiores do mesmo tipo - entretanto não haveria uma regra hipotética deste tipo ao final da cadeia. Com efeito, o autor entende que a união de regras de dois níveis formaria o centro de qualquer sistema jurídico, mas, em seu entorno, acomodar-se-iam os fundamentos da existência do próprio sistema: que as regras primárias, que são válidas de acordo com a regra de reconhecimento última do sistema, seriam geralmente obedecidas (mas não necessariamente aceitas), e que as regras secundárias seriam necessariamente aceitas ${ }^{4}$ pelos funcionários do sistema como o standard sociocomportamental (PAYNE, 1976, p. 288).

De outro lado, Dworkin acrescenta que a prática de um sistema de regras tende a levar à construção de uma "atitude interpretativa" quanto àquele sistema, fundado na presunção de que o sistema não apenas existe, mas tem um valor, e que a melhor observância deste valor, deste propósito, pode modificar as regras propriamente ditas (2014, p. 56-67).

Assim, assentada a atitude interpretativa, a observância ao sistema deixa de ser mecânica e os sujeitos passam a tentar impor significado ao sistema, reestruturando-o à luz desse significado. Daí extrai-se que, se se quer compreender o Direito, deve-se adotar a atitude interpretativa - ou seja, devemos admitir que o Direito deve ter um propósito e construir as normas individuais de acordo com esse propósito (DWORKIN, 2014, p. $56-67)$.

A concepção apresentada por Hart de que, nos pontos mais obscuros, as normas jurídicas poderiam ser incertas, cabendo ao juiz extirpar a incerteza da melhor forma possível, exercendo algum grau de discri-

\footnotetext{
${ }^{4}$ A diferença entre obediência e aceitação residiria no fato de que nesta há a adoção de um "ponto de vista interno" que leva o agente a reputar que uma dada regra justifica um comportamento (ou fundamenta uma crítica ao comportamento diverso).
} 
cionariedade, foi criticada por Dworkin. Para ele, não há qualquer discricionariedade na função do tribunal (mesmo confrontado com um "hard case"), na medida em que a solução do litígio, se não extraível da própria legislação, deveria advir dos princípios subjacentes a ela (DWORKIN, 2010, p. 127-128).

Reconhecendo a possibilidade de princípios (ou conjuntos de princípios) concorrentes, Dworkin sustenta que o julgador deve ter por correta a solução apontada pelo princípio (ou conjunto) mais adequado à história institucional do sistema legal que deve resolver o conflito (DWORKIN, 2014, p. 271-275). Para ele, haveria "consistência normativa” em um sistema (integridade), de forma a objurgar todas as decisões incompatíveis com essa consistência, mesmo que oriundas de princípios do próprio sistema (DWORKIN, 2014, p. 213-223, 263-269).

\subsection{Niklas Luhmann - o Direito no contexto dos sistemas sociais autopoiéticos}

Sob o ponto de vista luhmanniano, a definição de sociedade e de seus componentes é considerada por meio da teoria dos sistemas sociais, "ante a insuficiência das teorias sociológicas clássicas frente aos novos questionamentos advindos dos avanços/complexidades sociais” (ROCHA; SCHWARTZ; CLAM, 2005, p. 71-72).

Nesse sentir, Luhmann parte do pressuposto da real existência dos sistemas (Ibidem, p. 67), devendo-se atentar a qualquer análise/conceito de sociedade partindo dos fatos apresentados nos sistemas. Em suma, falar em sociedade é referir-se a sistemas, como assevera Luhmman: " $L a$ societé se compose de comunnications, seulement de communications et de tout les communications" (AMADO apud ROCHA; SCHWARTZ; CLAM, 2005. p. 70). 
Em essência, os sistemas sociais seriam sistemas de comunicação, e a sociedade seria o mais amplo desses sistemas. Nas palavras de Luhmman,

la sociedade es el concepto social más amplio, incluye todo lo social e, por consiguiente, no conoce ningún entorno social. Si se agregan factores sociales, si surgen interlocutores o temas de comunicación novedosos, la sociedad crece, pues esos factores arraigan en la sociedade, no pueden ser externalizados ni tratarse como una cosa de un entorno, ya que todo lo que es comunicación es sociedade (1998, p. 71).

Deve-se acrescentar, ainda, que cada sistema definir-se-ia por sua capacidade de diferenciação do meio, servindo essencialmente como redutor de complexidade. Logo, isto significa que, no interior de cada sistema, a abundância de informações do meio é selecionada, na medida em que o critério para a seleção seria o sentido que advém do próprio meio. Ademais, cada sistema manteria uma identidade distintiva (dos demais sistemas), constantemente reproduzida na comunicação sistêmica (ROCHA, 2013, p. 329-355).

Esse processo de reprodução de identidade, a partir de elementos previamente "filtrados" do meio hipercomplexo, seria a autopoiese (LUHMANN, 2007, p. 46). Tem-se, assim, um sistema fechado (porque o mundo exterior é "filtrado" pela linguagem, pelos paradigmas lato sensu, como forma de reduzir a complexidade) mas aberto (por suas curiosidades, verificações, interações, etc.) - sendo o paradoxo inerente aos sistemas autopoiéticos.

Quanto ao Direito, em específico, Luhmann contesta tanto a doutrina analítica (positivismo), porque muito fragmentária, quanto a doutrina hermenêutica, porque muito aberta. Para ele, o Direito é um sistema social que tem por função a estabilização e a generalização congruente de 
expectativas comportamentais normativas (2005, p. 92-106), tendo, como os demais sistemas, a função de reduzir a complexidade do ser (dos sistemas psíquicos) e do comportamento social.

Por esse motivo, o Direito não seria "primariamente um ordenamento coativo, mas sim um alívio para as expectativas. $O$ alívio consiste na disponibilidade de caminhos congruentes generalizados para as expectativas [...].” (LUHMANN, 2005, p. 101). Sendo autorreferente, contudo, o Direito retira sua validade de si mesmo, não podendo importá-la do exterior do sistema jurídico - é esta a sua clausura operacional e sua autonomia (MORIN, 2003, p. 14). A administração da justiça (aplicação do Direito a casos concretos) seria, portanto, expressão de autopoiese social.

\section{LÓGICA AUTOPOIÉTICA}

A compreensão da complexidade não mais se identifica com as formas clássicas de compreensão do mundo, porém, para que viabilizemos o desenvolvimento da compreensão na complexidade, é necessário sabermos como será estruturada essa compreensão.

Assim, ao pretendermos compreender a complexidade, deveremos fornecer elementos complexos, como instrumentos a serem articulados no desenvolvimento da compreensão. Dessa forma, a lógica autopoiética pretende estruturar a epistemologia da complexidade, podendo ser compreendida como o sistema que está simultaneamente ligado ao passado, presente e futuro; é aberta e fechada, possui repetição e diferença, equacionando em seu interior esse paradoxo, o qual será articulado para filtrar as informações referentes ao seu próprio sistema, estando, assim, intimamente ligada a um critério de repetição e diferença simultânea (ROCHA, 2013, p. 332-337). 
Dependendo de qual sistema ou subsistema pretendemos compreender o mundo, partimos de sua lógica pluralista local, que "relativiza as ideias extrasistemáticas de validade e verdade lógica, e, portanto, a ideia da correção de um sistema lógico, a uma área específica do discurso. Um argumento não é simplesmente válido, e ponto final” (HAACK, 2002, p. 291).

Levando em consideração a contingencialidade do ambiente como elemento essencial para a produção da lógica autopoiética, o entorno necessita de informação, para que, no complexo de desordem, possa desenvolver a ordem auto-organizada (ROCHA; SCHWARTZ; CLAM, 2005, p. 36).

A relação do observador não mais se verifica entre sujeito-objeto, e sim entre sujeito-sujeito, quando ele se autorreferencia. A lógica deixa de ser um sistema independente e matematificado, e a sociedade, por consequência, deixa de ser a simples soma das interações ou ações presentes, validadas como verdadeiras ou falsas, para ser vista como uma ordem maior, uma inter-relação entre valores de verdade difusos, determinada pela diferença entre sistema e ambiente. Assim, compreendendo a sociedade como policontextural (ROCHA, 2013, p. 345), diversos sistemas lógicos interagem de forma complementar, sem preponderância de nenhum.

O sistema autopoiético (ROCHA; SCHWARTZ; CLAM, 2005, p. 38-39) articulará a informação entre sistema e ambiente em uma recursão operativamente fechada e cognitivamente aberta, baseada em elementos fundamentais que estruturam e caracterizam seu sistema, como a polivalência não enumerada na lógica difusa ou os direitos humanos e fundamentais, no princípio da dignidade da pessoa humana, quando se pensa em Direito, por exemplo, articulados com valores de verdade difusos, evidenciados pelo meio, na inter-relação.

A partir da lógica autopoiética e da teoria dos sistemas, nas palavras de Rocha, Schwartz e Clam, 
[...] o sistema do Direito é operativamente fechado e cognitivamente aberto ao mesmo tempo. Em outras palavras, o sistema do Direito é autopoiético, isto é, reproduz de forma condicional os seus elementos diferenciando-se de suas consequências cognitivas. $\mathrm{O}$ sistema do Direito é constituído por uma lógica que articula a repetição e a diferença. Deste modo, autopoiese não é sinônimo de sistema fechado. É preciso livrar-se das amarras da lógica clássica que, fundamentada no princípio da não-contradição, não nos permite pensar a riqueza da alteridade. A rediscussão dos fenômenos vistos como paradoxos na qualidade de condição para a observação da comunicação do Direito será uma das grandes características desta nova forma de sociedade (2005, p. 47).

Em suma, a policontexturalidade é a forma contemporânea de se encaminhar a problemática do sentido do Direito. Por isso a importância do recurso ao conceito de autopoiese e seu elemento principal - a comunicação - como forma de aprofundar os estudo sobre o sentido.

\section{COMPLEXIDADE E MULTICULTURALISMO: Uma Reflexão Necessária Para o Direito}

O desenvolvimento de uma compreensão da complexidade e do multiculturalismo deve ser considerada a partir da reflexão autopoiética. Nesse sentido, a (re)fundação de um novo paradigma de compreensão passa pela(o) superação/aprimoramento do paradigma de relação sujeito-objeto, para o/e pelo paradigma de relação sujeito-sujeito, como anteriormente exposto, principalmente por intermédio da comunicação que se autorreproduz (TAUCHERT, 2011), instrumentalizando-a com o paradigma da linguagem. Possibilitaremos, dessa maneira, a criação de uma epistemologia da complexidade, ou seja, a forma de desenvolver os pressupostos de compreensão do complexo. 
Quando compreendemos a complexidade, desvelamos as infinitas possibilidades de relações e inter-relações entre o sistema e os subsistemas. Por sua vez, no multiculturalismo desvelamos o mosaico de possibilidades culturais produzidas a partir de sua inter-relação proporcionada pela linguagem, quando podemos compreender o outro como altero, como sujeito, tornando possível uma relação intercultural baseada em validações e valores difusos e autorreprodutores (BERTASO, 2007, p. 57-83).

Nesse sentido, a questão do multiculturalismo é temática extremamente importante para a sociedade atual, sendo profundamente essencial tecer sobre suas nuanças. Com efeito, o referido tema tem sido hoje cada vez mais utilizado não somente nos meios acadêmicos e políticos, mas no cotidiano, por uma gama variada de pessoas, estando seu significado associado a diversos sentidos, o que faz com que esta proliferação do termo não contribua para estabilizar ou esclarecer seu significado (HALL, 2006, p. 51).

O termo multiculturalismo não é compreendido e estudado de um excepcional modo.

Segundo afirmam Bhikhu e Parekh, "a palavra pode significar tanto a existência de duas ou mais culturas dentro de um determinado território, quanto o processo político de reinvindicação de direitos para cada uma das formas de manifestação cultural” (apud LUCAS, 2013, p. 185-186).

Por sua vez, Clancini afirma que o multiculturalismo é entendido

[...] como programa que prescreve cotas de representividade em museus, universidades e parlamentos, como exaltação indiferenciada das realizações e misérias daqueles que compartilham a mesma etnia ou o mesmo gênero, entrincheira-se no local sem problematizar sua inserção em unidades sociais complexas de ampla escala (CLANCINI, 2009, p. 26-27). 
De outro lado, a convivência de diferentes culturas em uma mesma sociedade é entendida, por Javier de Lucas, como

[...] multicultariedade, como fato social que, em razão da inevitável pluralidade, deve ser considerado existente independemente de ser avaliado positiva ou negativamente, enquanto o termo multiculturalismo é reservado para designar as reinvindicações políticas e as normas que tratam de reconhecer institucionalmente esta mesma multicultariedade (apud LUCAS, 2013, p. 186).

De fato, o termo multiculturalismo não tem uma única e exclusiva acepção, sendo, não raras vezes, desconhecido ou até mesmo confundido como sinônimo de multiculturalidade, o que sequer procede, segundo as palavras dos autores supracitados.

Por outro lado, ao compreendermos o Direito racionalmente, baseado em pressupostos metodológicos predefinidos que atuam como regras imutáveis, estabelecemos aprioristicamente as inviabilidades de compreendermos a sociedade contemporânea, pois o fluxo relacional do sujeito, tanto local quanto global, está para além do sistema jurídico imperativo. Esse sistema de raízes estatais modernas não possui mecanismos e instrumentos eficientes e eficazes de corresponder juridicamente às relações e inter-relações do sujeito, em um contexto atual de conexão local e global em rede (CASTELLS, 1999).

Ao tentarmos interpretar a sociedade contemporânea com preposições estanques, nos enclausuramos em pressupostos inadequados, inviabilizantes de qualquer compreensão da multiculturalidade e complexidade que vivenciamos. Logo, é necessário proporcionar uma compreensão da sociedade baseada em sua própria complexidade, para, então, proporcionarmos ao operador do Direito as possibilidades substanciais de tornar-se intérprete do Direito. 
Dessa forma, devemos possibilitar uma reflexão “que considere não só a organização e a vida das ideias em sistemas, teorias e doutrinas, não só a lógica, mas também [...]” (MORIN, 2002, p. 30), a epistemologia.

Assim sendo, o

[...] problema-chave da comunicação e da compreensão entre as idéias, as teorias, as visões do mundo, numa palavra, entre indivíduos e entre culturas. Temos que considerar a grande dificuldade que as teorias têm em comunicar umas com as outras (MORIN, 2002, p. 31).

Nesta perspectiva, a possibilidade da comunicação é dada no momento em que desenvolvermos a inter e a transdisciplinaridade entre as teorias, para que seja possível articulá-la com outras teorias que, ligadas em rede, formam a teoria do conhecimento complexo. Articulamos a compreensão do Direito a partir da compreensão da própria sociedade, na forma da lógica autopoiética.

Nunca foi tão necessária uma teoria comunicativa quanto nos tempos atuais, mas não as teorias do consenso (HABERMAS, 2005), que buscam respostas construídas para sociedades monoculturais, e sim teorias que trabalhem a complexidade, como a teoria sistêmica, adequada ao multiculturalismo.

Os pensamentos convencionais encontram-se despreparados para trabalhar novas complexidades ante a seus ordenamentos fechados. Da simplicidade monocultural os Estados foram conduzidos à complexidade multicultural, necessitando de rápidas respostas às novas questões sociais, legais e políticas, dentre outras.

Segundo Hall (2006, p. 7), “as velhas identidades, que por tanto tempo estabilizaram o mundo social, estão em declínio, fazendo surgir novas identidades e fragmentando o indivíduo moderno, até aqui visto como um sujeito unificado”, criando as crises constantes de identidade. 
Ocorre que, além dos problemas legais, a construção de um novo conhecimento multicultural passa por dificuldades.

Nesta ordem de ideias, Rocha salienta que

A teoria dos sistemas de Luhmann tem, assim, proporcionado a configuração de um novo estilo científico mais apto à compreensão das atuais sociedades complexas em que se vive, estando no centro das discussões atuais sobre o Direito e a Sociedade (2005, p. 102).

Assim, a teoria sistêmica, perante sua estrutura dinâmica, é capaz de reprocessar as informações advindas do sistema social, inovando e evoluindo os conhecimentos advindos das novas realidades multiculturais.

Nas palavras de Teubner,

O direito constitui um sistema autopoiético de segundo grau, autonomizando-se em face da sociedade, enquanto sistema autopoiético de primeiro grau, graças à constituição auto-referencial dos seus próprios componentes sistémicos e à articulação destes num hiperciclo (1989, p. 53).

A teoria sistêmica de Luhmann é uma teoria social, fixada pela comunicação, tendo uma íntima interação social com o entorno, que, por sua vez, acaba gerando a complexidade, que estabelece a criação de sistemas que se tornam subsistemas, tais como jurídicos, políticos e econômicos, dentre outros.

Quanto maior a necessidade de comunicação, maior será a complexidade, bem como maior será a expansão dos sistemas e subsistemas. Assim, trabalhando a complexidade social/multicultural, poderemos chegar a novas soluções para as questões ainda abertas em nosso sistema.

Por outro lado, a autorreflexividade e a capacidade de se auto-organizar sistemicamente em um hiperprocesso de reformulação de sentidos, são premissas básicas para desenvolver uma teoria crítica na sociedade moderna em que atualmente vivemos. 
Com efeito, a teoria piramidal de Kelsen pensou encontrar a panaceia para o problema do entorno jurídico, trabalhando o sistema na forma de enclausuramento, no qual as respostas são produzidas unicamente em seu interior de forma endógena (apud ROCHA 2005, p. 67-79).

Por sua vez, Luhmann e os adeptos da teoria autopoiética evidenciam a circularidade e a autorreferência do direito, ou seja, o sistema é fechado, porém aberto. É fechado, pois se utiliza apenas de seus códigos; e é aberto, pois sofre interferência de outros sistemas os quais são filtrados pelos códigos internos próprios, formando uma clausura normativa e abertura cognitiva (TEUBNER, 1989, p. 27).

\section{COMO FAZER CIÊNCIA DO DIREITO NA COMPLEXIDADE?}

Diante do contexto atual em que vivemos, devemos entender o nosso próprio objeto de estudo, que é o Direito, sob pena de preconizarmos visões equivocadas, na medida em que restringimos o entendimento às esfera abstratas das normas.

Em suma, reduzimos o Direito à lei e a pesquisa científica ou o fazer Ciência do Direito a simplesmente estudar uma parte do sistema social (Direito), como se os demais entes e subsistemas sequer existissem no entorno daquele.

Nesse sentido, assim como o corpo humano é complexo e, para o seu bom funcionamento, depende de todos os seus membros saudáveis, $o$ próprio Direito também é um ente complexo, que vai muito além do direito positivado e depende do seu entorno. 
Por isso, diante do estudo epistemológico da Ciência do Direito, que estabelece elementos de alcance que possibilitam identificar o que é o conhecimento científico e diferenciá-lo dos demais saberes jurídicos, é de suma importância o presente estudo para a qualificação da pesquisa científica do Direito, construindo-a em bases sólidas.

Dessa forma, podemos afirmar que sem uma definição clara do que é fazer Ciência na área jurídica e de como se faz pesquisa científica nesse campo, continuaremos pouco produzindo e pouco conhecendo sobre o nosso próprio objeto de estudo.

À vista disso, para falarmos em pesquisa científica do Direito, levando em consideração o atual cenário de complexidade, é necessário, primeiramente, estabelecermos o que é o Direito, na medida em que existem distintas maneiras de perceber o Direito, além do direito positivado (lei).

Nesse sentido, muito embora exista o direito representado por um código normativo ou, em outras palavras, o direito positivado, essa não é a única dimensão do Direito, que é, em última instância, um ente social altamente complexo, no qual encontram-se diversas dimensões sociais, políticas, econômicas, culturais e ambientais. Logo, se a pesquisa do Direito quer ser científica, também deve ser complexa, de modo a abarcar toda a complexidade das outras dimensões perpetuadas em seu entorno.

Outro ponto crucial nesse ínterim, diz respeito ao equívoco generalizado sobre a análise dos fenômenos jurídicos presentes no sistema, na medida em que é preciso chegar à fonte e não às consequências, como comumente tem se feito. Tal hipótese vem carceada na visão de Lyra Filho, quando afirma que as questões jurídicas ou as investigações sobre o Direito não podem ser colocadas, nem resolvidas, sem a consciência de que estão ligadas à percepção de uma adequada visão do Direito. $\mathrm{Ou}$ 
seja, considerando-se que o Direito admite variadas abordagens, recaímos numa falácia quando percebemos, num discurso jurídico formal, a abrangência do fenômeno em sua totalidade (1980, p. 6-8).

Em termos gerais, o Direito é amplo, pois configura um fenômeno social, e, justamente por isso, engloba também a faceta normativa. Por essa razão, deve haver a possibilidade de uma abordagem do Direito que delineie os pontos de integração do fenômeno jurídico na vida social, e que verifique o entrosamento dos diferentes aspectos, o que, no pensamento de Lyra Filho, se dá por intermédio de um modelo dialético. Esse modelo

[...] há de ser aberto e com a preocupação constante de encarar os fatos, dentro duma perspectiva que enfatiza o devir (a transformação constante) e a totalidade (a ligação de todos os segmentos da realidade, em função de conjunto). Somente dessa forma é que podemos apreender o pluralismo no direito (1980, p. 14).

Em essência, trata-se de um pensamento de caráter holístico, que implica proposta teórica na qual existe um indisfarçável idealismo, fruto da influência hegeliana.

Nesse sentido, a pesquisa científica do Direito deve ser complexa, isto é, baseada num estudo das conexões dos campos que perfazem o Direito a partir de um método dialógico. Assim, por exemplo, acaso o problema da pesquisa se vincule exclusivamente à positividade do Direito, faz-se necessário uma análise de suas conexões, de sua relação com a sociedade, com a política, com a economia, dentre outros subsistemas.

Diante disso, a ampla “[...] inversão que se produz no pensamento jurídico tradicional é tomar as normas como Direito e, depois, definir o Direito pelas normas, limitando estas às normas do Estado e da classe e grupos que o dominam” (LYRA FILHO, 1982, p. 118-119). Sem embargo, o Direito não se reduz às normas. 
Por conseguinte, uma pesquisa científica do Direito na complexidade deve se pautar pelas relações humanas na sociedade, concretamente nas esferas que a permeiam, tendo como escopo a análise das intersecções das instâncias sociais que permitiram o aparecimento desse ordenamento, assim como contrapô-lo à própria vida em sociedade, a fim de analisar seus resultados concretos.

Por isso que o grave problema que a pesquisa e as teorias jurídicas contemporâneas apresentam, é que elas normalmente reduzem, na organização de sua argumentação, o direito ao direito positivado pelo Estado, silenciando o seu surgimento do próprio seio da sociedade, não raras vezes confundindo o dever ser das normativas jurídicas com o próprio ser do Direito (o social).

Em termos gerais, no que respeita a uma possível solução para a Ciência do Direito, cumpre referir que, obviamente, não é nenhum tipo de positivismo, pois este percebe o Direito somente como ordem e controle social (LYRA FILHO, 1981, p. 30).

Noutro norte também não está nos tipos de jusnaturalismo, pois faz apelos de índole nitidamente idealista, não possuindo base social.

Desse modo, acredita-se que fazer Ciência do Direito requer uma pesquisa da complexidade dos fenômenos e do contexto social do qual emerge. Nesse sentido, por ser parte constitutiva do meio, embora com ele não se confunda, o humano é permeado pela sua complexidade social, política, econômica, cultural, ambiental, etc. Assim, ele é, embora não em última instância, um ser contextual, temporal e, geograficamente, um ser histórico.

Simplificadamente, o Direito surge como um regulador da vida em sociedade ou, em outras palavras, como uma abstração da mente humana ou um produto social. Refere-se, contudo, a uma abstração de um algo 
concreto da sociedade (um problema), que requer uma solução (teoria, conjectura, lei, etc.) concreta para esse problema. Justamente por essa vinculação dupla com o social, com o concreto, é que o Direito é complexo.

Daí porque todo o estudo ou pesquisa que verse sobre um tema relacionado à vida humana (em sociedade), como o Direito, por exemplo, importa numa análise complexa, que se preocupe com as relações entre as dimensões que permeiam essa vida, posto que os fenômenos são inter-relacionados, sob pena de uma análise reducionista do objeto de pesquisa e de uma caracterização de não cientificidade.

Justamente por isso, consideramos que o fazer Ciência do Direito implica delimitação entre o que é pesquisa científica e o que não é; isso porque a ciência se presta à solução de problemas, ou, nas palavras de Kuhn (1998), de "quebra-cabeças, que no caso do Direito são jurídicos e sociais”.

Essa visão de ciência nos permite intentar a erradicação das teorias do Direito que não mantêm uma correspondência empírica com a sociedade ou que subsistem meramente por meios de sustentação retórica ou ideológica.

\section{CONSIDERAÇÕES FINAIS}

A proposta deste trabalho era, ao prover uma sistematização das principais características das três principais matrizes epistemológicas do Direito (analítica, hermenêutica e pragmática), demonstrar a complexidade do meio em que vivemos, em especial a reproduzida na sociedade em rede. Pretendeu-se, inicialmente, mostrar que essa complexidade não pode nem deve ser encoberta pelo Direito, sob pena de ter-se um sistema inadequado para lidar com as nuances das questões complexas. Espera-se que a opção metodológica do trabalho - que evitou adentrar minúcias fáticas, permanecendo atrelado essencialmente à construção teórica da epis- 
temologia - não prejudique a demonstração que se quis fazer no que diz respeito à reformulação da forma como produzimos nosso conhecimento e, por consequência, dos pressupostos de interpretação e compreensão do Direito e da sociedade, para que as respostas que produziremos sejam correspondentes à realidade, sejam claras, precisas e bem-definidas, coerentes ao contexto onde estarão sendo proferidas, representando, de maneira eficaz, sua realidade social.

Como pesquisadores, docentes, discentes e todos os intérpretes do Direito, teremos de refletir essa nova proposta para que proporcionemos as respostas que a sociedade espera de todos nós, e para que respondamos adequadamente à complexidade, contingência, intersubjetividade e à conexão das relações sociais em forma de rede, que definem a sociedade contemporânea e desafiam o Direito e sua reflexão.

De maneira simplificada, o pensamento complexo é um incentivo para que os pesquisadores possam alcançar uma nova visão do mundo, que seja dialógica e que perceba esse mundo, inclusive os fenômenos humanos, de maneira inter-relacionada; em suma, para que se considere a complexidade de cada questão a ser estudada.

E assim, sendo o Direito também um ente social, a definição do estatuto epistemológico da Ciência do Direito estabelece critérios de demarcação que possibilitem identificar o que é o conhecimento científico e diferenciá-lo dos demais saberes jurídicos, o qual é de vital importância para a qualificação da pesquisa jurídica científica.

Com efeito, o Direito surge como um regulador da vida em sociedade. Assim, enquanto teoria, ele é uma abstração que advém do próprio concreto da sociedade (um problema), que requer uma solução concreta para esse problema. 
Nesse sentido, uma pesquisa científica do Direito na complexidade deve se pautar pelas relações humanas na sociedade, concretamente nas esferas que a permeiam, visando à Justiça Social. Quer dizer, ainda que a pesquisa tenha por objeto o direito enquanto ordenamento jurídico ou parte dele, deve ela analisar as intersecções das instâncias sociais que permitiram o aparecimento desse ordenamento, assim como contrapô-lo à própria vida em sociedade, a fim de analisar seus resultados concretos.

Ou seja, deve haver uma preocupação metodológica com as relações entre as dimensões que permeiam essa vida, uma vez que os fenômenos são inter-relacionados, sob pena de uma análise reducionista do objeto de pesquisa e de uma caracterização de não cientificidade.

\section{REFERÊNCIAS}

AMADO, Juan Antonio García. La Société et le Droit Chez Luhmann. In: ROCHA, Leonel Severo; SCHWARTZ, Germano; CLAM, Jean. Introdução à teoria do sistema autopoiético do Direito. Porto Alegre: Livraria do Advogado, 2005.

BERTASO, João Martins. Cidadania e demandas de igual dignidade: dimensão de reconhecimento na diversidade cultural. In: OLIVEIRA JUNIOR, José Alcebíades de (Org.). Faces do multiculturalismo: teoria, política, direito. Santo Ângelo: Ediuri, 2007.

CANCLINI, Néstor García. Narrar o multiculturalismo. In: Consumidores e Cidadãos: conflitos multiculturais da globalização. Rio de Janeiro: UFRJ, 2009. CASTELLS, Manoel. O poder da identidade. In: CASTELLS, Manoel. A era da informação: economia, sociedade e cultura. São Paulo: Paz e Terra, 1999. DWORKIN, Ronald. Levando os direitos a sério. São Paulo: Martins Fontes, 2010.

. O império do direito. São Paulo: Martins Fontes, 2014.

HAACK, Susan. Filosofia das lógicas. São Paulo: Unesp, 2002. 
HABERMAS, Jürgen. Facticidad y validez. Tradução Manuel Jiménez Redondo. Madrid: Trotta, 2005.

HALL, Stuart. A identidade cultural na pós-modernidade. Tradução Tomaz Tadeu da Silva e Guacira Lopes Louro. Rio de Janeiro: DP\&A, 2006.

HART, Herbert Lionel Adolphus. O conceito de Direito. Lisboa: Fundação Calouste Gulbenkian, 1996.

KELSEN, Hans. Teoria pura do Direito. São Paulo: Martins Fontes, 1998.

KUHN, Thomas Samuel. The Structure of Scientific Revolution. University of Chicago Press, 1998.

LUHMANN, Niklas. El Derecho de la Sociedad. Cidade do México: Universidad

Iberoamericana, 2005. . La sociedad de la sociedad. Cidade do México: Herder, 2007. . Sistemas Sociales: lineamentos para una teoría general. México: Anthropos, 1998.

LUCAS, Doglas Cesar. Direitos humanos e interculturalidade: um diálogo entre a igualdade e diferença. 2. ed. Ijuí: Ed. Unijuí, 2013.

LYRA FILHO, Roberto. O Direito que se ensina errado. Brasília: Centro Acadêmico de Direito da UnB, 1980.

. O que é Direito? São Paulo: Brasiliense, 1982.

. Problemas atuais do ensino jurídico. Brasília: Obreira, 1981.

MORIN, Edgar. Introdução ao pensamento complexo. Lisboa: Instituto Piaget, 2003. 2002.

O problema epistemológico da complexidade. Lisboa: Mem Martins,

PAYNE, Michael. Hart's Concept of a Legal System. William and Mary Law Review, vol. 18, ed. 2, 1976.

ROCHA, Leonel Severo (Org.). Paradoxos da auto-observação: percursos da teoria jurídica contemporânea. Ijuí: Ed. Unijuí, 2013.

Epistemologia jurídica e democracia. São Leopoldo: Unisinos, 2005. 
ROCHA, Leonel Severo; SCHWARTZ, Germano; CLAM, Jean. Introdução à teoria do sistema autopoiético do Direito. Porto Alegre: Livraria do Advogado, 2005.

TAUCHERT, Maicon Rodrigo. Sintaxe, semântica e pragmática-sistêmica. Compreensão e desenvolvimento de uma lógica autopoiética a partir do paradigma da linguagem. 2011. Disponível em: <http://www.uj.novaprolink.com. br>. Acesso em: 4 mar. 2016.

TEUBNER, Gunther. O direito como sistema autopoiético. Tradução José Engrácia Antunes. Lisboa: Fundação Calouste Gulbenkian, 1989. 